\title{
Resources for sports engineering education
}

\author{
Tom Allen ${ }^{1}$ (i) $\cdot$ John Eric Goff ${ }^{2}$
}

Published online: 25 September 2017

(C) The Author(s) 2017. This article is an open access publication

\begin{abstract}
This paper serves as a resource guide for Sports Engineering educators. The paper covers key topics in Sports Engineering, including ball impact, friction, safety and materials. A variety of resource types are presented to reflect modern methods of learning and searching for information, including textbooks, research and review papers, websites and videos. The field could benefit from more resources specifically designated for teaching Sports Engineering, particularly textbooks.
\end{abstract}

Keywords Physics · Impact · Friction · Safety · Materials · Biomechanics

\section{Introduction}

This paper is intended to act as a guide for academics who wish to use sports examples as part of a University level engineering or physics curriculum. The guide is predominantly targeted at those teaching at undergraduate level, although the resources highlighted should also be suitable for postgraduate students, particularly those being introduced to Sports Engineering. It is envisaged that this resource will be most beneficial to those new to teaching, or experienced academics wishing to bring sporting examples into their classroom for the first time. It may also serve as a resource guide for students with an interest in

Tom Allen

t.allen@mmu.ac.uk

1 Sports Engineering Research TEAM, Manchester Metropolitan University, Manchester M15 6BH, UK

2 Department of Physics, Lynchburg College, Lynchburg, VA 24501, USA
Sports Engineering. This paper was inspired by two resource letters by Frohlich [1, 2], and it focuses predominantly on resources published since the second paper in 2011. Whereas Frohlich focussed on Sports Physics, this paper covers Sports Engineering in the broader sense, encompassing engineering, technology and physics.

The paper is structured around the following topics, which should form the core of a Sports Engineering curriculum: (1) historical sporting performance, (2) sports rules and regulations, (3) projectile aerodynamics, (4) vehicular aerodynamics, (5) ball impact, (6) friction in sport, (7) disability sports, (8) safety in sport, (9) materials, manufacturing and sports products and (10) sports biomechanics. Each section signposts the reader to a variety of resources, including textbooks, special issues, review papers, research papers, standards and regulations and online resources, such as videos and the websites of governing bodies. The resources highlighted do not represent all of those available, rather some noteworthy examples are highlighted with the intention that they serve as a starting point. Videos and websites tend to be introductory in nature, making them well suited for introducing topics, putting them into context, inspiring students and encouraging discussion and debate. In contrast, journal papers are more suitable when covering complex theories and showcasing the latest research. Examples are highlighted with the intention that they serve as a starting point. Selections are based upon the authors' own teaching experiences, recommendations from peers, and what they have seen as cutting-edge topics in Sports Engineering. Instructors may have an internationally diverse group of students, some of whom may be exposed to certain sports for the first time. Simple, introductory videos may provide some students their first look at a given sport, exposure that will be invaluable when instructors move to more complicated aspects of the sport. 
An ideal first port of call for those interested in Sports Engineering is the online video collection from the Royal Institution, featuring Professor Steve Haake from Sheffield Hallam University [3]. Elsewhere, Driscoll et al. [4] discuss the role of images in teaching sports mechanics, while highlighting some nice examples. New academics may also wish to refer to Hubisz's [5] tips for young physics teachers. The European Journal of Physics launched a focus collection on Physics of Sport in 2016 [6] and other papers in this Education Special Issue of Sports Engineering should also be useful to teachers.

\section{Books covering the engineering and physics of sport}

There are a number of books dedicated to the broad topics of the Engineering and Physics of Sport, which should serve as a good starting point. Fuss et al. [7] is the first handbook dedicated to Sports Engineering and Technology, and there are a number of recent releases on sports physics [8-11]. Easterling [12] gives a broad overview of materials within sports equipment, while Hong [13] covers ergonomics in sport. Those interested in sportswear and performance apparel could refer to Hayes and Venkatraman [14]. Dixon et al. [15] provide an excellent summary of the science and engineering of sports surfaces, while Goonetilleke [16] provides a detailed account of the science of footwear.

There are also some more specific Sports Engineering and Physics books. Denny [17] and Braghin et al. [18] cover the physics of winter sports, with Haché [19] focusing on ice hockey. Haché's release is less mathematical than its 2002 predecessor, "The Physics of Hockey" [20]. Dewhurst [21] focusses on the physics of golf, while Minton [22] explains the statistics behind the game. Glaskin [23] covers the science of cycling. Seifert and Chollet [24] is a comprehensive book on the science of swimming, including a section on Biomechanics.

Noerstrud [25] addresses Sports Aerodynamics. Peters [26] is part of the "Lecture Notes in Computational Science and Engineering" series and it contains five articles covering various sports, as well as standard equations, approaches to computational fluid dynamics (CFD), and flow visualization images.

\section{Historical sporting performance}

A suitable opener for a Sports Engineering course is the topic of historical sporting performance and the role of technology. It is essential to impress upon students how much science and technology have influenced sports. Such an introduction to the course has great potential to whet their appetites for careers in Sports Engineering. Students should see the progression in athletic training, how modelling has become ever more powerful and influential, and the way organising bodies have responded to new technologies infused in various sports. An early introduction to the aforementioned topics also sets the stage for later course discussions. Besides providing them with a historical overview of Sports Engineering's growing influence in sports, students should be presented with the current state of affairs so that they may set their sights on a specific field where they'll want to tackle open questions or contribute to the development of new technologies.

A delightful starting point for an instructor preparing a course is the entry level video from the Science Show [27]. Dyer's [28] review paper focuses on the controversy of sports technology, which could serve useful in an introductory class, or when selecting topics for essays and debates. David Epstein's 2014 Ted Talk [29] provides an overview of how athletes have developed and become more specialised, and his 2013 book [30] could serve as background reading for those particularly interested in this topic. A number of scientific papers have investigated how sporting performance has improved over time [31-35], and they could be useful when introducing basic physics, mathematical modelling and statistics.

Balmer et al. [31] fitted mathematical models to historical performance data for jumping events, including pole vault, triple jump, long jump and high jump. They attributed performance gains in pole vault with the introduction of fibreglass poles in 1956, combined with a period of postwar growth. The 'Fosbury Flop,' which helped Dick Fosbury win gold at the 1968 Olympics, was attributed to performance gains in high jump. The physics behind the Fosbury Flop is explained in Asaf Bar-Yosef's visually pleasing TED-Ed Original talk [36]. Balmer and coworkers [31] concluded that these jumping events appear to have reached a peak, and technological improvements are needed if performances are to improve.

Haake and colleagues used a performance index — based on work done by the athlete-to quantify performance improvements in running [33] and field events, including high jump, pole vault and javelin [34]. Using similar techniques to Haake and colleagues, Dyer [32] highlighted greater performance improvements in running events for lower limb amputees in comparison to able-bodied athletes, highlighting the influence of technology on disability sport. Preston and Johnson [35] investigated the role of technology in swimming record breaks, highlighting the influence of swimsuits. Combined with the Fédération internationale de natation (FINA) requirements for swimwear [37], Preston and Johnson's work makes a nice topic for a case study. The ethical issues associated with enhancing 
performance with engineering are complex, and the topics discussed by James [38] are well suited for a discussion, debate or essay.

\section{Sports rules and regulations}

Students may initially struggle to see the relevance of discussing a given sport's governing body. But an instructor should be able to quickly remove that struggle with a couple of examples that illustrate the relationship between Sports Engineering and the rules of the game. One such example concerns swimming. Scientists and engineers developed the Speedo LZR polyurethane swimsuits for the Beijing Olympics in 2008. Even NASA contributed to the technology. When nearly all of the races were won by swimmers sporting the new suit and almost two dozen new records were established, FINA stepped in and changed the rules the following year. Another example concerns cycling. The arms race between doping technologies and detection technologies is ongoing. Governing bodies often need help from sports engineers when rules are in need of modification.

The websites of sports governing bodies often contain a wealth of information, which can be useful for showcasing how theory is put into practice when setting rules and regulations. These websites typically contain the rules of the game and details of how equipment is tested and regulated. The websites of golf's governing bodies [39, 40] summarise the science behind the game while showcasing how equipment is regulated. The "Science of Golf Video Series" produced as a collaboration between the United States Golf Association (USGA) and the National Broadcasting Company (NBC) Learn is well produced with clear explanations [41, 42]. Similar video collections from NBC Learn [43] include, "Science of NHL Hockey", "Science of the NFL Football", "Science of the Summer Olympics", "Science of the Olympic Winter Games" and "Science and Engineering of the 2014 Olympic Winter Games".

The website for the International Tennis Federation (ITF) Technical Department includes a summary of testing procedures and facilities, the history of tennis equipment and the rules of tennis [44]. The National Collegiate Athletic Association (NCAA) website contains rules, rules changes, and rules surveys for the entirety of university sports played in the US [45]. While not a governing body, the website of the Sports Science Laboratory at Washington State University summarises the work of Professor Lloyd Smith and his team on baseball and softball equipment, showcasing how scientific work can influence rules and regulations [46]. Standards for testing baseball and softball equipment which can be readily applied to teaching include, ASTM F2398-11, ASTM F2219-14 and ASTM F1888-09.
The Fédération Internationale de Football Association (FIFA) quality programmes website contains background information and details on standards, including Goal-Line Technology, Footballs and Football Turf [47]. The FIFA football turf handbook of test methods contains protocols that could be applied to theoretical and practical sessions [48]. Sections of the handbook covering determination of (1) football rebound, (2) ball roll and (3) shock absorption are particularly relevant to engineering students. For those more interested in rugby, Regulation 12 provides an insight into how player dress is regulated and tested [49].

\section{Projectile aerodynamics}

No Sports Engineering course is complete without a section devoted to projectile aerodynamics. Most, if not all, students in such a course will have solved a standard projectile motion problem in which air resistance is ignored. Such a starting place is essential, but often the results are wildly different from reality. Incorporating the reality of sports played in air introduces students to the rich field of aerodynamics. They will need to be exposed to physical and mathematical models that have been developed to predict a projectile's motion through air, and they will need to see examples of how projected sports objects, be they people or equipment, are tested in laboratories. Including air resistance in projectile problems complicates matters, especially if numerical techniques are required, often to the extent that students are surprised at just how much attention is needed to solve problems they once thought of as simple.

Because the aerodynamics of projectiles is such a key topic for aspiring sports engineers, a review of the field may be the best starting point, and Goff's [50] review paper is well suited to this role. Goff explains the basic physics before summarising recent work across a range of sports. Other papers that lend themselves well to teaching cover the physics of ski jumping [51], baseball trajectory modelling [52], magnus force [53] and golf ball drag [54]. Cross [54] showcases a simple experiment to measure the drag on a golf ball by dropping it into a water tank.

Magnus force [55] is introduced in an entertaining TEDEd Original video. Videos explaining and showcasing the aerodynamics of sports balls can also be found on YouTube, with noteworthy examples including, "Science of Golf: Why Golf Balls Have Dimples", "CFD Visualization Comparing Turbulent Vortex Shedding Between a Sphere and Golf Ball", "Testing the World Cup Ball in a

\footnotetext{
${ }^{1} \mathrm{https} / / / \mathrm{www}$. youtube.com/watch? $\mathrm{v}=$ fcjaxC-e8oY.

${ }^{2}$ https://www.youtube.com/watch?v=GHOoZYhF6r4.
} 
NASA Wind Tunnel", 3 "Ames Research Center Tests World Cup Soccer Ball" and "Tennis Ball in Wind Tunnel". 5

\section{Vehicular aerodynamics}

Nearly all of the students in a Sports Engineering course will have felt air rushing over their hands while sticking those hands out of car or bus windows. Start with a simple connection like that so that students will have an immediate feel for the topic of vehicular aerodynamics. Such a connection also works when discussing aerodynamics in general. Give practical numbers at the start, such as what percentage of a car's petrol-use goes to overcome air drag. Compare a car or bus, a vehicle they are familiar with, to a race car or a Tour de France bicycle. For the latter comparison, discuss how much human power output goes to fighting air resistance. Then tell students how much time could be cut off a cyclist's stage time if just, say, $2 \%$ power output could be moved from fighting the air to upping the speed a little. Students may then understand why equipment, auto, bicycle, and clothing manufactures invest so much money into making their products more aerodynamic. Do not hesitate to tell students that a significant portion of that money goes toward sports engineers.

The majority of the work on vehicle aerodynamics has focussed on cycling, and the recent review paper by Crouch et al. [56] is comprehensive. Barry et al. [57] cover wind tunnel testing of cyclists in a team pursuit. Theilmann and Reinhard [58] explore the physics of a moving cyclist, including an example spreadsheet that can be used for teaching. In a similar style, Driscoll et al. [59] explain the physics of a gravity racer, while also including a basic model in an example spreadsheet.

Professor Bert Blocken's website is a useful resource for anyone interested in the aerodynamics of cycling [60]. As per the aerodynamics of sports balls, a number of videos can be found on YouTube and noteworthy examples include, "TU Delft wind tunnel to gain aero advantage with 3D printed mannequin of Tom Dumoulin", "CFD Simulation of a Pedaling Cyclist", "Sled CFD analysis for 'Speed with Guy Martin", ${ }^{\prime}$ and "bobsleigh skeleton CFD simulation".

\footnotetext{
${ }^{3}$ https://www.youtube.com/watch?v=9p2w5Zg52uo.

${ }^{4}$ https://www.youtube.com/watch?v=PH7cbLfxmbM.

5 https://www.youtube.com/watch?v=k-Vtu-39oWE.

${ }^{6} \mathrm{https}: / / \mathrm{www}$. youtube.com/watch? $\mathrm{v}=\operatorname{mrEDNOxJud8}$.

${ }^{7} \mathrm{https}: / / \mathrm{www}$.youtube.com/watch? $\mathrm{v}=\mathrm{sdYmJ}$ SJcZE.

${ }^{8} \mathrm{https}: / / \mathrm{www}$. youtube.com/watch?v=2M2Nv-vGnso.

${ }^{9} \mathrm{https}: / /$ www.youtube.com/watch? $=\mathrm{Jdyd} 9 \mathrm{~V} 0 \mathrm{KNe}$.
}

\section{Ball impact}

Impress upon students just how short some collisions in sport last. They will obviously be familiar with times in seconds, minutes, and hours. But they may not have much connection to the roughly $2 \mathrm{~ms}$ that a head is in contact with a fast-moving football or the just over $1 \mathrm{~ms}$ time that a baseball and bat are in contact. Connect to what students may be familiar with. Before telling a student that a header in football happens in the blink of an eye, consider that an eye blink takes about 100 times longer to execute than the time needed to head a football.

There is a wealth of papers on the mechanics of ball impact. Cross' review [61] describes the mechanics of ball/surface and ball/implement impacts, while introducing modelling techniques using examples from baseball and tennis. In more recent work, Cross [62] provides straightforward explanations of the mechanics of a normal and oblique ball bounce. Elsewhere, Widenhorn [63] describes the physics of the unusual scenario where a football bounces off both goalposts during a penalty shot. There are some noteworthy reviews of the mechanics of tennis rackets [64-66]. Meanwhile, Spurr et al. [67] highlight experiments for measuring the moment of inertia of a tennis racket, which could lend themselves well to laboratory classes. Spurr and colleagues showcase experiments for calibrating their setup using rods of known moment of inertia. Alternative methods for measuring the moment of inertia of a tennis racket can be found in Brody et al. [68].

There are also some informative papers describing the physics of softball and baseball bats. Smith and Kensrud [69] compare field measurements of ball and bat speeds with laboratory experiments, Kagan [70] focusses on bat vibrations, Aguilar and Kagan [71] describe the mechanics of breaking a baseball bat through a simple experiment with wooden dowels and Nathan et al. [72] exposes the physics of cheating. Eftaxiopoulou et al. [73] describe the mechanics of cricket bats, comparing designs from different eras. Allen et al. [74] is a straightforward short communication on the mechanics of stick/ball interactions in field hockey, with high-speed video image sequences showcasing impact mechanisms. Widenhorn [75] covers the physics of juggling a ping-pong ball with a bat.

\section{Friction in sport}

As an instructor begins a new section of a Sports Engineering course, a good pedagogical idea is to seek students' opinions. Is friction good or bad? Do athletes and engineers primarily try to reduce friction or enhance it? Get students thinking about the new topic with questions in their heads. 
Air friction may have already been discussed, so students may think that reducing friction is what is more often done. If so, ask students if friction between their shoes and the floor is helpful when they walk and run. Emphasize that friction is a concept involving two objects interacting with each other, and steer clear of ascribing friction to just one object.

Issue seven of volume 226 of the Journal of Engineering Tribology was dedicated to Tribology of Sport, edited by Matt Carré and Roger Lewis [76]. The entirety of volume sixteen, issue four of Sports Engineering was devoted to Winter Sports [77], with skiing discussed in most of the papers. Pertinent to this section was a paper on ice friction associated with a speed skate blade [78]. Elsewhere, Poirier et al. [79] presented an experimental analysis of ice friction in bobsleigh. Clarke et al. [80] illustrated the key components of studying shoe/surface interactions. Very recent research has identified a critical hole area ratio, which is the ratio of dimpled hole area to the total shoe contact area, for tennis shoes sliding on a hard court [81]. Allen et al. [82] showcase the effect of friction on tennis ball impacts.

\section{Disability sport}

One of the greatest contributions from sports engineers is developing the equipment needed to allow disabled athletes to compete in numerous sports. There are likely to be students in a Sports Engineering course who are motivated by the idea that they can contribute towards helping those previously shut out from athletic competition. Making sports more inclusive is not restricted to the elite athletes. A satisfying career may be had by helping disabled children in primary and secondary schools share in the joy of competing at sport.

Issues one and two in volume five of Sports Technology were dedicated to Paralympic Sports Technology [83]; issue three in volume nineteen of Sports Engineering was dedicated to Technology for Disability Sport [84]. These special issues serve as an ideal starting point for papers on the topic of disability sport. Readers can also refer to the Official website of the Paralympic Movement, where they can find rules and procedures [85].

\section{Sport safety}

It should not be hard to motivate students that safety is of paramount importance in sport. The topic of safety comes in many guises, from equipment specially designed to protect athletes, to improved training methods that help athletes avoid injury, to assisting governing bodies in establishing rules and guidelines for removing athletes from competition after they are deemed a greater health risk following a collision. Engineers also make contributions to technologies that get injured athletes back into competition in shorter times than in the past. Impress upon students that though safety is important, so is the excitement in a given sport. Making heading illegal in football may help reduce concussions, but much would be lost from the beautiful game. There is always a cost/benefit analysis that must be done when designing safety equipment and establishing rules to protect athletes.

Issue one in volume 230 of Sports Engineering and Technology was dedicated to Personal Protective Equipment in Sport [86]. This special issue serves as an ideal starting point for papers on the topic of sport safety. Linking research to standards and regulations can help to build case studies around sport safety equipment. Michel et al. [87] summarises the challenges related to wrist injuries and prevention in snowboarding, and the website of the International Society for Skiing Safety [88] provides details of a project to develop an ISO standard for wrist protectors (ISO/CD 20320). Elsewhere, the website for ASTM International has a section for publications sponsored by the committee on Sports Equipment, Playing Surfaces and Facilities [89], with papers and conference proceeding on safety, including a collection on concussion mechanisms [90].

Head injuries and helmet design are important topics and scientific interest is growing around the issue of concussion. David Camarillo's recent TEDx talk "Why helmets don't prevent concussions_and what might" [91], is a suitable place to start. Kuhn et al. [92] is a review paper connected to youth helmet impacts. Such studies are needed for the reduction of concussions in youth sports. Post et al. [93] provide an excellent summary of head injury measurement criterion. Brügger et al. [94] provide an overview of issues related to snow sport helmets, and related standards include EN1077 and ASTMF2040. Another video, this time from the Athlete Recovery Fund, exposes the importance of wearing a certified helmet when cycling [95].

The website of the National Operating Committee on Standards for Athletic Equipment (NOCSAE) [96] is also an excellent resource, with information on research related to sport safety and standards for equipment. Academic publications can be used to showcase how NOCSAE protocols can be applied to assess equipment, such as lacrosse helmets [97] and lacrosse and football helmets [98]. Recently, the Sports Technology Institute at Loughborough University developed a test to assess for penetration of a ball through a cricket helmet [99, 100], which was implemented into a revised standard [101], BS 7928:2013 Specification for head protectors for cricketers. Other standards that lend themselves well to teaching include, BS 
6183-1:1981 Protective equipment for cricketers, EN 13061: 2009 Shin guards for association football players and EN 13158:2009 Protective Jackets, Body, \& Shoulder Protectors for Horse Riders.

\section{Materials, manufacturing and sports products}

Students thinking about careers will definitely be interested in this section of Sports Engineering. Instructors are encouraged to invite engineers and managers to offer a guest lecture or two, or take their students to visit companies. Even if companies want to keep their cutting-edge research to themselves because of fierce competition in the sports world, students will surely benefit from the commentary and advice offered by those working for companies in which technology is emphasised perhaps as much as profit.

Though there are not so many papers detailing materials in sports equipment-perhaps because research is often funded by industry and remains proprietary-there are some nice examples. A recent special issue in Materials and Design was entitled Recent Advances in Materials for Sports Technology [102]. Caine et al. [103] provide a comprehensive overview of materials in sport. Kai [104] gives an insight into the science and engineering behind golf balls from an industry perspective. Allen et al. [105] highlight the potential for auxetic foam to be applied to snow sport safety devices, and this paper could assist with teaching material fundamentals, such as stress, strain and Poisson's ratio. Recent work by Lippa et al. [106, 107] demonstrates how to mechanically age running shoes and assess degradation.

Resources on the design of sports equipment are limited in number. Wilson et al. [108] present a design process model for sports equipment. Elsewhere, patents can serve as useful tools for showcasing noteworthy designs and products, which can support case studies. Howard Head revolutionised ski design in the 1950s; his laminated construction techniques combined different materials and provided a plastic running surface [109]. Head went on to patent a tennis racket in the 1970s with a larger sized head [110], which made it easier to hit the ball and paved the way for modern designs. Fischer's 'Spaghetti String Racket' [111] allowed the player to impart more topspin on the ball and was banned by the ITF shortly after its release. Leimer et al. [112] showcase an intriguing design for an actively ventilated sports shoe with a built in fan, and recent patents highlight the emergence of auxetic materials and structures in footwear [113] and apparel [114].

YouTube contains a wealth of videos showcasing how sports equipment is manufactured and tested, with noteworthy examples including, "How It's Made-
Shuttlecocks", 10 "How The New World Cup Balls Are Made", "adidas Brazuca Production", 12 "Researchadidas JABULANI Official Match Ball of the 2010 FIFA World Cup", 13 "Made in Japan-Mizuno Football Factory Visit", 14 "HEAD Making of: Tennis Racquets", 15 "How a Tennis Racquet is Made", "16 "See How To Make A Snowboardl Whitelines Snowboarding" 17 and "ANSYS Sports Engineering". 18

\section{Biomechanics}

The field of athletic training now occupies entire departments in universities and colleges around the world. Humans continue to get taller, stronger, faster, and are able to compete in sports for more years than athletes of the past. Advances in diet, nutrition, exercise, and training produce athletes in today's world capable of pushing the laws of physics to the limits of their constraints. Sports engineers use computer models to optimize player movements to maximise performance. For example, Ralph Mann's video analysis work at CompuSport helped US sprinter Carmelita Jeter shave time off her 100-m dash [115].

Issues three and four in volume 226 of Sports Engineering and Technology were dedicated to Impact Biomechanics in Sport [116]. This special issue serves as an ideal starting point for papers on the topic of biomechanics, although a number of papers are focussed on sport safety equipment and materials. Stefanyshyn and Wannop's [117] review gives an overview of the role of biomechanics in sports equipment development. Kagan [118] is an entry level look at the physics of stealing a base in baseball. The relationship between the inertia of a striking implement, such as a racket or bat, and the maximum speed that the user can swing it, is a topic of much debate. Cross [119] covers the basic mechanics of swinging an object, such as a tennis racket, whereas Schorah and colleagues [120] provide a more detailed account of the problem.

ESPN's Sports Science [121] contains well-funded and well-made videos that analyse elite athletes and special plays in sports. In a similar style, Star Talk's 'Playing with

\footnotetext{
${ }^{10} \mathrm{https}: / / \mathrm{www}$. youtube.com/watch?v=czkDCBgZAns.

${ }^{11} \mathrm{https} / / / \mathrm{www}$.youtube.com/watch?v=WzPZi0DxDnA.

$12 \mathrm{https} / / / \mathrm{www}$.youtube.com/watch? $\mathrm{v}=\mathrm{tRXLEbzJefs}$.

$13 \mathrm{https} / / / \mathrm{www}$.youtube.com/watch?v=-Nz8MOe4XQY.

$14 \mathrm{https} / / / \mathrm{www}$. youtube.com/watch?v=Nr4GdJXpbPU.

15 https://www.youtube.com/watch?v=JMBqPbLrZMA.

$16 \mathrm{https}: / /$ www.youtube.com/watch? $\mathrm{v}=\mathrm{sg}$ V2DMstyPo.

17 https://www.youtube.com/watch?v=S_zvez-oMHQ.

18 https://www.youtube.com/watch?v=e4Z564ZAAzY.
} 
Science Episodes' are podcasts where experts discuss the science of sport [122]. Though not strictly sport, Arleen Sugano TED-Ed Original video, "The physics of the "hardest move" in ballet" [123] is excellent.

\section{Conclusion}

Resources that lend themselves well to teaching Sports Engineering have been highlighted. Though some topics, such as the history of sporting performance, ball impact and aerodynamics are relatively well covered in the literature, other areas appear to have fewer resources, including materials, design and the interaction between biomechanics and sports equipment. There are few high-quality resources designated specifically for teaching Sports Engineering. Research papers can be adopted for teaching to some extent, and though sports physics is reasonably well covered, there is a lack of literature specifically intended for Sports Engineering education. Some excellent videos are available for teaching Sports Engineering. Those produced as a collaboration between an organisation with sports engineering expertise, such as a university or governing body, and a video producer have proved fruitful, and this approach should be encouraged. The field of Sports Engineering would benefit from resources specifically developed for teaching this exciting subject, particularly if an up-to-date reference list could be held in a central location, such as the website of the International Sports Engineering Association.

More textbooks dedicated to Sports Engineering would be beneficial. There are, however, many challenges associated with creating a Sports Engineering textbook. Should the book contain background material on basic physics topics, such as mechanics and fluids? Or should the book leave those topics to other courses? Should individual sports be used as examples for engineering topics or should entire chapters be devoted to individual sports? To satisfy a wide range of instructors' interests, a Sports Engineering textbook might have to be a rather large tome. This paper represents an alternative to a textbook for a Sports Engineering course, which may be a course not particularly suited for one textbook. Using this paper as a starting point, instructors new to a Sports Engineering course should be able to select from the references given here and then design the course they want to teach.

Open Access This article is distributed under the terms of the Creative Commons Attribution 4.0 International License (http://crea tivecommons.org/licenses/by/4.0/), which permits unrestricted use, distribution, and reproduction in any medium, provided you give appropriate credit to the original author(s) and the source, provide a link to the Creative Commons license, and indicate if changes were made.

\section{References}

1. Frohlich C (1986) Resource letter PS-1: physics of sports. Am J Phys 54:590-593

2. Frohlich C (2011) Resource letter PS-2: physics of sports. Am J Phys 79:565-574

3. Haake (2012) Engineering sport: Ri channel. http://richannel. org/collections/2012/engineering-sport. Accessed 8 Mar 2017

4. Driscoll H, Hart J, Allen T (2016) Use of image based sports case studies for teaching mechanics. Procedia Eng 147:884-889

5. Hubisz JL (2013) Over 50 years of teaching physics-some advice for young teachers. Phys Teach 51:188-189

6. Choppin S, Fösel A (2016) Focus on physics of sport. http:// iopscience.iop.org/journal/0143-0807/page/Focus-on-Physicsof-Sport. Accessed 2 May 2017

7. Fuss FK, Subic A, Strangwood M, Mehta R (eds) (2013) Routledge handbook of sports technology and engineering. Routledge, New York

8. Goff JE (2010) Gold medal physics: the science of sports. JHU Press, Baltimore

9. Kruger Wrobel (2016) Physics in sports, 1st edn. JASK Press, LLC, Overland Park

10. Spathopoulos VM (2013) An introduction to the physics of sports. CreateSpace Independent Publishing Platform, Lexington

11. Vizard F (2008) Why a curveball curves: the incredible science of sports. Hearst Books, New York

12. Easterling E (2012) Advanced materials for sports equipment: how advanced materials help optimize sporting performance and make sport safer. Springer Science \& Business Media, Dordrecht

13. Hong Y (ed) (2013) Routledge handbook of ergonomics in sport and exercise. Routledge, New York

14. Hayes SG, Venkatraman P (eds) (2015) Materials and technology for sportswear and performance apparel. CRC Press, Boca Raton

15. Dixon S, Fleming P, James I, Carré M (eds) (2015) The science and engineering of sport surfaces. Routledge, New York

16. Goonetilleke RS (ed) (2012) The science of footwear. CRC Press, Boca Raton

17. Denny M (2011) Gliding for gold: the physics of winter sports. JHU Press, Baltimore

18. Braghin F, Cheli F, Maldifassi S, Melzi S, Sabbioni E (eds) (2015) The engineering approach to winter sports. Springer, New York

19. Haché A (2015) Slap shot science: a curious fan's guide to hockey. JHU Press, Baltimore

20. Haché A (2002) The physics of hockey. JHU Press, Baltimore

21. Dewhurst $P$ (2015) The science of the perfect swing. Oxford University Press, New York

22. Minton R (2012) Golf by the Numbers. JHU Press, Baltimore

23. Glaskin M (2013) Cycling science: how rider and machine work together. University of Chicago Press, Chicago

24. Seifert L, Chollet D (eds) (2011) World book of swimming: from science to performance. Nova Science Publishers, New York

25. Nørstrud H (ed) (2009) Sport aerodynamics, vol 506. Springer Science \& Business Media, New York

26. Peters M (ed) (2009) Computational fluid dynamics for sport simulation. Springer, Berlin

27. Science Show (2016) Why are some world records so hard to break? https://www.youtube.com/watch?v=d0OoAD8WFfI. Accessed on 26 Apr 2017

28. Dyer B (2015) The controversy of sports technology: a systematic review. SpringerPlus 4:524 
29. Epstein D (2014) David Epstein: are athletes really getting faster, better, stronger? https://www.ted.com/talks/david_ epstein_are_athletes_really_getting_faster_better_stronger. Accessed 8 Mar 2017

30. Epstein D (2013) The sports gene: inside the science of extraordinary athletic performance. Penguin, London

31. Balmer N, Pleasence P, Nevill A (2012) Evolution and revolution: gauging the impact of technological and technical innovation on Olympic performance. J Sports Sci 30:1075-1083

32. Dyer B (2015) The progression of male $100 \mathrm{~m}$ sprinting with a lower-limb amputation 1976-2012. Sports 3:30-39

33. Haake SJ, Foster LI, James DM (2014) An improvement index to quantify the evolution of performance in running. J Sports Sci 32:610-622

34. Haake S, James D, Foster L (2015) An improvement index to quantify the evolution of performance in field events. J Sports Sci 33:255-267

35. Preston EC, Johnson DK (2015) Fastest in the pool: the role of technological innovation on swimming record breaks. IJIMT 6:353

36. Bar-Yosef A (2014) TED-Ed Original, An athlete uses physics to shatter world records. http://ed.ted.com/lessons/an-athleteuses-physics-to-shatter-world-records-asaf-bar-yosef. Accessed 8 Mar 2017

37. FINA (2017) FINA Requirements for Swimwear Approval, 2017 edn. https://www.fina.org/sites/default/files/frsa.pdf. Accessed 11 Apr 2017

38. James D (2010) The ethics of using engineering to enhance athletic performance. Procedia Eng 2(2):3405-3410

39. R\&A (2017) R\&A rules and equipment. http://www.randa.org/ RulesEquipment/. Accessed 11 Apr 2017

40. USGA (2017), USGA rules, equipment. http://www.usga.org/ content/usga/home-page/equipment-standards.html. Accessed 11 Apr 2017

41. USGA (2017) USGA STEM Resource Centre. http://www.usga. org/stem. Accessed 11 Apr 2017

42. NBC Learn (2017) Science of golf. http://www.nbclearn.com/ science-of-golf. Accessed 11 Apr 2017

43. NBC Learn (2017) NBC Learn Resources. http://www.nbclearn. com/portal/site/learn/resources. Accessed

44. ITF (2017) ITF Technical Department web resource. http:// www.itftennis.com/technical/. Accessed 8 Mar 2017

45. NCAA (2017) Governing body for university sports in the US. Numerous links to various sports rules, summaries of rules changes, and sports rules surveys. http://www.ncaa.org/. Accessed 2 Apr 2017

46. Sports Science Laboratory (2017). https://ssl.wsu.edu/. Accessed 11 Apr 2017

47. FIFA (2017) FIFA quality programme web resource. http:// quality.fifa.com/en/. Accessed 8 Mar 2017

48. FIFA (2012) FIFA quality concept for football turf handbook of test methods, January 2012 edn. https://football-technology.fifa. com/media/1015/football_turf_handbook_of_test_methods_ 2012.pdf. Accessed 8 Mar 2017

49. World Rugby (2015) Regulation 12-provisions relating to players' dress, 2012 edn. http://playerwelfare.worldrugby.org/ ?documentid=51. Accessed 8 Mar 2017

50. Goff JE (2013) A review of recent research into aerodynamics of sport projectiles. Sports Eng 16:137-154

51. Rębilas K (2013) Optimal Ski Jump. Phys Teach 51:108-109

52. Kagan D, Nathan AM (2017) Statcast and the baseball trajectory calculator. Phys Teach 55:134-136

53. Timková V, Ješková Z (2017) How magnus bends the flying ball-experimenting and modeling. Phys Teach 55:112-114

54. Cross R (2016) Effects of turbulence on the drag force on a golf ball. Eur J Phys 37:054001
55. Garty E (2015) Football physics: The "impossible" free kick. http://ed.ted.com/lessons/football-physics-the-impossible-freekick-erez-garty. Accessed on 26 Apr 2017

56. Crouch T, Burton D, Blair K, Labry Z (2017) Riding against the wind: a review of competition cycling aerodynamics. Sports Eng 20:81-110

57. Barry N, Burton D, Sheridan J, Thompson M, Brown NAT (2015) Aerodynamic drag interactions between cyclists in a team pursuit. Sports Eng 18:93-103

58. Theilmann F, Reinhard C (2015) Exploring the aerodynamic drag of a moving cyclist. Phys Educ 51:015001

59. Driscoll HF, Bullas AM, King CE, Senior T, Haake SJ, Hart J (2016) Application of Newtonian physics to predict the speed of a gravity racer. Phys Educ 51:045002

60. Blocken B (2017) Urban physics, wind engineering \& sports aerodynamics. http://www.urbanphysics.net. Accessed $11 \mathrm{Apr}$ 2017

61. Cross R (2014) Impact of sports balls with striking implements. Sports Eng 171:3-22

62. Cross R (2015) Behaviour of a bouncing ball. Phys Educ 50:335

63. Widenhorn R (2016) Hitting the goalpost: calculating the fine line between winning and losing a penalty shootout. Phys Teach $54: 434-438$

64. Allen T, Choppin S, Knudson D (2016) A review of tennis racket performance parameters. Sports Eng 19:1-11

65. Knudson D, Allen TB, Choppin SB (2013) Interaction of tennis racket design and biomechanical factors. In: Hong Y (ed) Routledge handbook of ergonomics in sport and exercise. Routledge, New York, pp 423-439

66. Miller S (2006) Modern tennis rackets, balls, and surfaces. Br J Sports Med 40:401-405

67. Spurr J, Goodwill S, Kelley J, Haake S (2014) Measuring the inertial properties of a tennis racket. Procedia Eng 72:569-574

68. Brody H, Cross R, Lindsey C (2002) The physics and technology of tennis. Usrsa, Solana Beach

69. Smith L, Kensrud J (2014) Field and laboratory measurements of softball player swing speed and bat performance. Sports Eng 17:75-82

70. Kagan D (2011) The vibrations in a rubber baseball bat. Phys Teach 49:588-588

71. Aguilar IC, Kagan D (2013) Breaking bat. Phys Teach 51:80-82

72. Nathan AM, Smith LV, Faber WL, Russell DA (2011) Corked bats, juiced balls, and humidors: the physics of cheating in baseball. Am J Phys 79:575-580

73. Eftaxiopoulou T, Persad L, Bull AM (2016) Assessment of performance parameters of a series of five 'historical' cricket bat designs. Proc Inst Mech Eng Part P. doi:10.1177/ 1754337116638970

74. Allen T, Foster L, Carré M, Choppin S (2012) Characterising the impact performance of field hockey sticks. Sports Eng $15: 221-226$

75. Widenhorn R (2016) The physics of juggling a spinning pingpong ball. Am J Phys 84:936-942

76. Carré M, Lewis R (2012) Special issue on tribology of sport. Proc Inst Mech Eng Part J 226:587

77. Federolf P, Strangwood M (2013) Special issue on winter sports. Sports Eng 16:195-196

78. Lozowski E, Szilder K, Maw S (2013) A model of ice friction for a speed skate blade. Sports Eng 16:239-253

79. Poirier L, Lozowski EP, Maw S, Stefanyshyn DJ, Thompson RI (2011) Experimental analysis of ice friction in the sport of bobsleigh. Sports Eng 14:67-72

80. Clarke J, Dixon SJ, Damm L, Carré MJ (2013) The effect of normal load force and roughness on the dynamic traction developed at the shoe-surface interface in tennis. Sports Eng 16:165-171 
81. Goff JE, Boswell L, Ura D, Kozy M, Carré MJ (2017) Critical shoe contact area ratio for sliding on a tennis hard court. Proc Inst Mech Eng Part P. doi:10.1177/1754337117715341

82. Allen T, Haake S, Goodwill S (2010) Effect of friction on tennis ball impacts. Proc Inst Mech Eng Part P 224:229-236

83. Van de Vliet P (2012) Editorial for paralympic sports technology. Sport Technol 5:2-3

84. Koptyug A, Burkett B (2016) Editorial for the special issue technology for disability sport. Sports Eng 19:139-139

85. Paralympic Movement (2017) Official website of the paralympic movement. https://www.paralympic.org/. Accessed 8 Mar 2017

86. Webster J (2016) Special issue on personal protective equipment in sport. Proc Inst Mech Eng 230:3-4

87. Michel FI, Schmitt KU, Greenwald RM, Russell K, Simpson FI, Schulz D, Langran M (2013) White Paper: functionality and efficacy of wrist protectors in snowboarding-towards a harmonized international standard. Sports Eng 16:197-210

88. ISSS (2017) Wrist Protector Working Group. http://www.isss web.com/wrist-protector-working-group/. Accessed 2 May 2017

89. ASTM (2017) Publications Sponsored by Committee F08 on Sports Equipment, Playing Surfaces, and Facilities. https:// www.astm.org/COMMITTEE/F08_pubs.htm. Accessed on 11 July 2017

90. Alan A, Mariusz Z (2014) Mechanism of concussion in sports. ASTM International, West Conshohocken

91. Camarillo D (2016) Why helmets don't prevent concussionsand what might. https://www.ted.com/talks/david_camarillo_ why_helmets_don_t_prevent_concussions_and_what_might. Accessed 2 May 2017

92. Kuhn EN, Miller JH, Feltman B, Powers AK, Sicking D, Johnston JM Jr (2017) Youth helmet design in sports with repetitive low- and medium-energy impacts: a systematic review. Sports Eng 20:29-40

93. Post A, Hoshizaki TB, Brien S (2014) Head injuries, measurement criteria and helmet design. In: Hong Y (ed) Routledge handbook of ergonomics in sport and exercise. Routledge, New York, pp 399-412

94. Brügger O, Bianchi G, Schulz D et al (2010) Snow-sport helmets: injury prevention, rate of wearers and recommendations. Berne: bfu-Swiss Council for Accident Prevention, EuroSafe Task Force Safety in Sports

95. Athlete Recovery Fund (2013) ARF Presents: certified vs noncertified bicycle helmet impact test. https://vimeo.com/ 55624399. Accessed on 5 May 2017

96. NOCSAE (2011) National Operating Committee on Standards for Athletic Equipment. http://nocsae.org/about-nocsae/. Accessed 4 May 2017

97. Bowman TG, Breedlove KM, Breedlove EL, Dodge TM, Nauman EA (2015) Impact attenuation properties of new and used lacrosse helmets. J Biomech 48:3782-3787

98. Breedlove KM, Breedlove EL, Bowman TG, Nauman EA (2016) Impact attenuation capabilities of football and lacrosse helmets. J Biomech 49:2838-2844

99. STI (2017) Loughborough University research to inform cricket helmet safety development. http://www.lboro.ac.uk/newsevents/news/2015/december/cricket-helmet-safety.html. Accessed 8 Mar 2017

100. Stone BW, Harland AR, Jones JP, Mitchell SR, Sherratt PJ, Ranson CA, Halkon BJ (2017) On the dynamic response of an instrumented headform for alternative mounting stiffnesses when subjected to ballistic impacts for the purpose of sports safety helmet evaluation. Proc Inst Mech Eng Part P. doi:10. 1177/1754337117703574

101. ECB (2017) ECB and PCA guidance: head protectors/helmets. https://www.ecb.co.uk/concussion-in-cricket/helmets. Accessed 8 Mar 2017

102. Dasari A, Chen Z, Huang WM, Sui T, Korsunsky AM (2016) Materials \& design virtual special issue: recent advances in materials for sports technology. Mater Des 99:592-593

103. Caine M, Blair K, Vasquez M (2012) Materials and technology in sport. Nature materials 11:655-658

104. Kai M (2008) Science and engineering technology behind Bridgestone tour golf balls. Sports Technol 1:57-64

105. Allen T, Duncan O, Foster L, Senior T, Zampieri D, Edeh V, Alderson A (2017) Auxetic foam for snow-sport safety devices. In: Scher I, Greenwald R, Petrone N (eds) Snow sports trauma and safety. Springer, Cham

106. Lippa NM, Krzeminski DE, Piland SG, Rawlins JW, Gould TE (2016) Biofidelic mechanical ageing of ethylene vinyl acetate running footwear midsole foam. Proc Inst Mech Eng Part P. doi: $10.1177 / 1754337116678153$

107. Lippa NM, Collins PK, Bonacci J, Piland SG, Rawlins JW, Gould TE (2017) Mechanical ageing performance of minimalist and traditional footwear foams. Footwear Sci 9:9-20

108. Wilson N, Thomson A, Riches P (2017) Development and presentation of the first design process model for sports equipment design. Res Eng Des. doi:10.1007/s00163-017-0257-4

109. Head H (1954) Composite wood and metal ski having plastic running surface. US Patent 2,694,580

110. Head H (1976) US Patent and Trademark Office, Washington, DC. US Patent 3,999,756

111. Fischer W (1981) US Patent and Trademark Office, Washington, DC. US Patent 4,273,331

112. Leimer R, Robinson T K, Michel F I, Manz G R, Gordon J R, Allen T, Harnisch M, Blinn J, Adidas International Marketing BV (2012) Actively ventilated shoe. US Patent 8,209,882

113. Cross TM, Nike Inc (2017) Footwear soles with auxetic material. US Patent 9,554,624

114. Blakely K S, Toronjo A, Under Armour Inc (2013) Articles of apparel with auxetic fabric. US Patent Application 14/137,250

115. Al-Jamea S, Berkowitz B, Contreras E, Downs K, Rubin M, Stanton L (2012) http://www.washingtonpost.com/wp-srv/spe cial/sports/profiles-in-speed/technology/. Accessed 4 May 2017

116. Gilchrist M, Rueda MF (2012) Special issue on impact biomechanics in sport. Proc Inst Mech Eng Part P 226:163-164

117. Stefanyshyn DJ, Wannop JW (2015) Biomechanics research and sport equipment development. Sports Eng 18:191-202

118. Kagan D (2013) Stolen base physics. Phys Teach 51:269-271

119. Cross R (2015) Physics of swinging a striking implement. Phys Educ 50:232

120. Schorah D, Choppin S, James D (2015) Effects of moment of inertia on restricted motion swing speed. Sports Biomech 14:157-167

121. ESPN (2017) Sports Science. http://www.espn.com/espn/sports cience/. Accessed 2 Apr 2017

122. StartTalk (2017) Playing with science episodes. https://www. startalkradio.net/category/playing-with-science/. Accessed 2 Apr 2017

123. Sugano A (2016) The physics of the "hardest move" in ballet. http://ed.ted.com/lessons/the-physics-of-the-hardest-move-inballet-arleen-sugano. Accessed 2 Apr 2017 